\title{
Micro-insurance in Bangladesh: Risk Protection for the Poor?
}

\author{
Wendy J. Werner* \\ 7 Abdullo Komandir Street, Dushanbe 73400I, Tajikistan \\ (*Former Consultant to ICDDR,B, GPO Box 128, Dhaka 1000, Bangladesh)
}

\begin{abstract}
Health services and modern medicines are out of reach for over one billion people globally. Micro-insurance for health is one method to address unmet health needs. This case study used a social exclusion perspective to assess the health and poverty impact of micro-insurance for health in Bangladesh and contrasts this with several micro-insurance systems for health offered in India. Micro-insurance for health in Bangladesh targeted towards the poor and the ultra-poor provides basic healthcare at an affordable rate whereas the Indian micro-insurance schemes for health have been implemented across larger populations and include high-cost and low-frequency events. Results of analysis of the existing literature showed that micro-insurance for health as currently offered in Bangladesh increased access to, and use of, basic health services among excluded populations but did not reduce the likelihood that essential health-related costs would be a catastrophic expense for a marginalized household.
\end{abstract}

Key words: Health expenditure; Health insurance; Microcredit; Microfinance; Micro-insurance; Poverty; Rural health services; Bangladesh

\section{INTRODUCTION}

Health services and modern medicines are out of reach for over one billion people globally (1). In many countries, including Bangladesh, barriers to public-health facilities force the poor to pay for healthcare out-of-pocket, often driving the poor further into poverty. Although a system of universal coverage may be ideal in many cases, there is a need for interim strategies to reduce out-of-pocket expenditure on health. Such strategies include mixes of community cooperative- and enterprise-based health insurance and social health insurance-type coverage for specific groups.

Micro-insurance is an emerging sector, strongly linked to the microcredit movement in Bangladesh. Despite the extensive reach of microcredit in South Asia, micro-insurance is still a nascent sector, with approximately 36.9 million lives in South Asia covered by some form of micro-insurance (2). There is substantial diversity in the programmes being offered in the subcontinent. This case study assessed the poverty and health impact of micro-insurance

All correspondence should be addressed to: (Reprints are not available from the author) Wendy J. Werner

7 Abdullo Komandir Street

Dushanbe 734001

Tajikistan

Email: wendywerner@gmail.com

Fax: +992-48-7011453 for health in Bangladesh, comparing these with the micro-insurance programmes for health in India.

This case study analysis of micro-insurance as a potential mechanism to address social exclusion draws from peer-reviewed and grey literature on microinsurance for health. Two basic questions with regard to micro-insurance for health were addressed: (a) Does micro-insurance for health increase access to, and use of, basic health services among excluded populations? and (b) Does micro-insurance for health reduce the likelihood that health costs will be a catastrophic expense for marginalized households?

Given the constraints of the existing literature and the scope of this exercise, the analysis is indicative.

\section{POTENTIAL OF MICRO-INSURANCE FOR HEALTH TO REDUCE EXLCUSION FROM HEALTH SERVICES}

Micro-insurance is designed generally to address economic exclusion from resources, services, and/ or social protection in the cases of death, ill-health, or another adverse life-event. Micro-insurance for health is also designed to rectify spatial exclusion from health services and cultural exclusion of women from health services. This case study focuses on the extent to which the micro-insurance schemes for health address spatial and economic barriers to healthcare among marginalized groups. 
Generally, people in rural areas in Bangladesh have lower access to public services and private-sector resources. The primary manifestation of spatial exclusion in healthcare is the lack of access to health services for women, rural people, and the poor. In Bangladesh, there are only 26 doctors and 30 hospital beds for every 100,000 people (3). Most of these resources are located in urban areas. Motivation for the micro-insurance schemes for health was, in many cases, driven by this spatial exclusion in access to health services. Microcredit organizations, for example, began providing micro-insurance for health because their members could not access staterun health clinics (4).

The poor have traditionally faced barriers to health services due to their poverty. Bangladesh has one of the highest rates of reliance on out-of-pocket health expenses in Asia. Out-of-pocket health expenses have negative consequences in the use of health services and overall living standards, primarily due to the unpredictable nature of out-of-pocket expenses (5). A significant portion of healthcare expenses in Bangladesh are privately funded, mostly as out-of-pocket expenses. Private sources finance $71 \%$ of national health expenditure; $88 \%$ of the costs for health in private sources is out-of-pocket expenditure (3) [Health costs in private facilities in Bangladesh comprised 88\% out-of-pocket expenditure, $10 \%$ non-profit institutions serving households, and $0.8 \%$ pre-paid and risk-pooling plans (3)]. More than $70 \%$ of the out-of-pocket expenses are for medicines, which reflects the high prevalence of self-medication due primarily to lower access to services for constraints relating to income and distance (5). Households, on average, spend $5 \%$ of household expenditure on out-of-pocket health costs (6). Free public-health services for the urban and rural poor only exist theoretically. The poor are largely excluded from the public facilities that do exist due to lack of money (for bakshish or bribes) or connections.

The actual distribution of health subsidies is not pro-poor. The poorest $20 \%$ of the population actually received only $16 \%$ of government health subsidies (7). If access to subsidized healthcare was targeted towards the poor, the share of the subsidy received by the poorest quintile would be greater than 20\%. Therefore, households with lower income and lower disposable income have reduced capacity to access health services.

High out-of-pocket health expenses leave a household vulnerable to the effects of catastrophic health expenses. Catastrophic health costs are those that severely disrupt household living standards by absorbing a large fraction (10-40\%) of household resources. Xu et al. found that catastrophic health expenditure is most likely to occur when health services require payment (i.e. are not free), households have a low capacity to pay, and in the absence of prepayment or health insurance (6). In Asia, Bangladesh has the highest incidence of catastrophic health payments. Using the measure of $40 \%$ of non-food expenditure as the standard for 'catastrophic expenses', $7 \%$ of households had experienced a catastrophic expense in the previous year. If the standard for 'catastrophic' drops to 15\%, 25\% of the population had experienced catastrophic expenses in the same time period (5). In Bangladesh, catastrophic out-of-pocket health payments could account for as much as $3.8 \%$ of the population falling below the poverty-line of $\$ 1$ per day (5).

Even for those households with the ability and funds to access basic health services, catastrophic health costs can push the household into poverty. In reaction to a catastrophic health expense, households can sell assets, access credit (from relatives, community, and money-lenders), or find additional sources of income. Additional income can come from reduction in consumption or increasing wage labour by other household members, including child labour (8). The impact of health on household wealth cannot be overstated. Ill-health causes a loss of income in two ways. First, the cost of treatment can, in many cases, use all income, and the household will be forced to borrow funds. This is especially true in Bangladesh where household outof-pocket is high. Second, lost income due to inability to work, both on the part of the ill household member and others who need to care for him/her, reduces current and future flow of income. Since poor households are largely rely on daily-wage income, its loss, coupled with high medical costs, can be crippling (2).

The health and economic status of socially-excluded populations is, therefore, based on access to both health facilities and ability to pay. Ability to pay can be further disaggregated into: (a) ongoing, low-cost basic and preventative health costs (2) and (b) high catastrophic health costs. To establish the impact of micro-insurance for health on the use of health services and, by extension, health and economic status, the impact on both types of costs should be examined. 


\section{MICRO-INSURANCE FOR HEALTH IN BANGLADESH WITH CONTRASTS FROM INDIA}

As microcredit has proven, financial services, such as access to credit, can have a positive impact on poor populations and can reach sustainability of market. Micro-insurance encompasses a range of different insurance services aimed at poor populations. Insurance can be even more important for low-income groups as they are more vulnerable to ill-health or death, unexpected expenses, and natural disasters. Micro-insurance is different from traditional insurance due to its lower premiums and lower profit margins; it is, therefore, of critical importance that micro-insurance systems are welladministered, cost-efficient, and delivered on a large scale. Despite the large natural market for microinsurance, the penetration of these products is quite low throughout developing countries. A recent global survey of micro-insurance estimates that 78.5 million lives are covered by micro-insurance, and 6.5 million lives are covered in Bangladesh, leaving $90-94 \%$ of the poor without micro-insurance coverage (2).

Globally, most micro-insurance policies are offered by private insurers (2). In Bangladesh, microcredit organizations are a prominent delivery channel and providers of micro-insurance. In many cases, life insurance is required for borrowers. As the concept of risk protection can be misunderstood among target populations, micro-insurance programmes use microlending, health outreach, and community information networks to market their products. Given that microcredit organizations have gained a high level of trust in the community, this has been a successful strategy (4).

There are three major types of micro-insurance offered in Bangladesh: health, life, and integrated. This case study discuses diverse examples of microinsurance for health in Bangladesh and presents contrasting micro-insurance schemes for health from India.

\section{Micro-health insurance in Bangladesh}

In Bangladesh, all the micro-insurance schemes (Table 1) for health follow the strategy of providing essential health services through low service pricing and affordable premium collection from a large group of the disadvantaged people. The health schemes in India have taken a different approach, covering some high-cost services and integrating health insurance with life and asset protection.

\begin{tabular}{|lc|}
\hline \multicolumn{2}{|c|}{$\begin{array}{c}\text { Table 1. Micro-insurance schemes in Bangla- } \\
\text { desh (4) }\end{array}$} \\
\hline Type of insurance & $\begin{array}{c}\text { No. of schemes } \\
(\mathrm{n}=36)\end{array}$ \\
\hline Health & 13 \\
Life & 12 \\
Loans/capital & 8 \\
Livestock & 2 \\
Disaster & 1 \\
\hline
\end{tabular}

In Bangladesh, micro-insurance for health is primarily provided by non-governmental organizations (NGOs) which also provide corollary health services and microcredit. Most micro-insurance programmes for health are linked to microloans and are reliant on the group dynamics of microcredit. For instance, the Society for Social Service requires every borrower to take out a health card for Tk 20 (US\$ 0.29) that enrolls them in the micro-insurance scheme for health. Most schemes run communitybased clinics staffed by medical professionals and paramedics and include labouratory facilities. Two schemes have large hospitals but other schemes use referrals for secondary and tertiary care (9). Copayments are required to reduce frivolous or unnecessary health consumption on the part of clients but co-payment amounts are designed to be affordable [The tendency to partake in unnecessary procedures or neglect prevention is referred to, in economic theory, as 'moral hazard' because the cost to the client is a small portion of the overall cost, and the client may, therefore, not take the full economic cost (i.e. price) into account when weighing the cost and benefits]. Most micro-insurance schemes for health have provision for the poorest to receive benefits without premium of co-payments.

Basic and preventive health services are covered by micro-insurance for health, including immunizations, family planning, consultation, and normal deliveries. Discounts are provided on medicines and pathology tests. Generally, hospitalization is covered up to Tk 1,000 (US\$ 14). The Society for Social Services is the lone benefit package that covers surgeries, for a co-payment of Tk 3,000 (US\$ 44) (Appendix).

The top three micro-insurance healthcare providers hold 115,000 policies, covering more than 550,000 people (10). However, micro-insurance for health only covers a limited number of districts in Bangladesh. The micro-insurance schemes for health target women and the poor, both microcredit members and others living in the areas covered by the schemes (9). These organizations have deliberately 
overlooked the risks of selecting a group of clients who have similar and possibly correlated health risks and have enrolled members without any restrictions (10). This lack of selectivity is consistent with the objectives of equity and community health; however, the micro-insurance organizations may be taking on a higher level of risk which needs to be adequately managed.

Most NGOs operating micro-insurance schemes for health in Bangladesh receive external funding to subsidize their programmes; only the Society for Social Service and the Dhaka Community Hospital have achieved 100\% recovery rate. Most micro-insurance schemes cross-subsidize ultra-poor participants from other subscribers. However, neither of the financially-viable programmes do this (9). Typical insurance programmes take 3-5 years to reach sustainability. Given that micro-insurance schemes are much more challenging, financial sustainability could take 7-10 years (11). For example, cost-recovery is higher when the number of policyholders is broad-based and large. The cost-recovery, subsidization, and funding profile of Bangladesh micro-health insurance schemes for health largely reflect the design and funding priorities (Table 2). To date, these schemes were additions to microcredit programmes or mechanisms to increase access to primary healthcare.

The micro-insurance schemes for health in Bangladesh have a number of common challenges. First, there is a general lack of understanding among the target market of insurance as a risk-management tool and a general aversion to paying for health services unless facing an illness or accident. Insurance premiums are largely seen as expenditure rather than an investment to protect assets and future income (10). Second, health service expectations are difficult to manage. Clients may have expectations that quality healthcare includes procedures that are, in many cases, unnecessary. For instance, patients may want a saline-drip for diarrhoea when oral hydration may be more effective and cost-efficient. Health education can affect perceptions of patients about required health services. Perceptions of the quality of healthcare have important implications for micro-insurance subscriptions and re-enrollment and, therefore, for overall financial viability of programmes (11). Third, controlling healthcare costs is generally a challenge for health-insurance companies, and micro-insurance is no different. One solution is to have a ceiling on the amount of benefits available, or to limit the recovery-time but such limitations transfer the financial burden back to clients and make the scheme less attractive to potential clients (10). The micro-insurance schemes for health in Bangladesh have largely tended to maintain affordability by limiting the services provided. Fourth, to move towards financial viability and accurately assess the impact and success of the insurance products, robust management information systems are required. Save for the largest insurers, most organizations do not have adequate management information systems to provide data on clients and claims (10). Fifth, healthcare costs, low re-enrollment rates, and a limited number of subscribers have, with a few exceptions, prevented the micro-insurance schemes for health in Bangladesh from achieving independent financial viability, i.e. they are reliant on donor-funding to cover shortfalls. Since sustainability has recently become increasingly important and technical assistance has been provided to improve management systems and quality of product, many of these issues will be or are being addressed. Even so, financial viability may still be some years in the future (9).

As the above discussion demonstrates, the microinsurance schemes for health in Bangladesh are designed to increase the use of, and access to, basic and preventative healthcare. Insurance products are designed to provide primary care at affordable prices but do not cover high-cost/low-frequency

\begin{tabular}{|lccc|}
\hline \multicolumn{4}{|c|}{ Table 2. Cost-recovery for micro-insurance schemes for health in Bangladesh (4) } \\
Organization & Recovery rate (\%) & $\begin{array}{c}\text { Cross subsidization } \\
(\mathrm{Y} / \mathrm{N})\end{array}$ & $\begin{array}{c}\text { External funding } \\
(\mathrm{Y} / \mathrm{N})\end{array}$ \\
\hline BRAC & $50-60$ & $\mathrm{Y}$ & $\mathrm{Y}$ \\
Grameen Kalyan & 77 & $\mathrm{Y}$ & $\mathrm{Y}$ \\
Dhaka Community Hospital & 100 & $\mathrm{~N}$ & $\mathrm{~N}$ \\
Dushtha Shasthya Kendra & $\mathrm{NA}$ & $\mathrm{Y}$ & $\mathrm{Y}$ \\
Nari Uddug Kendra & 10 & $\mathrm{Y}$ & $\mathrm{N}$ \\
Sajida Foundation & 53 & $\mathrm{Y}$ & $\mathrm{Y}$ \\
Society for Social Services & 100 & $\mathrm{~N}$ & $\mathrm{~N}$ \\
\hline N=No; NA=Not available; Y=Yes & & & \\
\hline
\end{tabular}


health services. For instance, only one scheme covers surgeries, and none explicitly covers caesarean delivery or emergency obstetric care.

There is clearly scope and need to expand even the basic and preventative micro-insurance for health both for microcredit borrowers and non-borrowers. Slightly less than seven million lives of a population of more than 140 million are covered in Bangladesh. Results of a study of rickshaw-pullers in Dhaka showed that NGOs were the most prominent source of formal sector credit but accounted for only $2 \%$ of medical treatment received (12). The same study has shown that financing healthcare was one of the top three reasons for borrowing by rickshaw-pullers. Extension of microcredit relationship to include health insurance could give the poor greater access to medical services. Micro-insurance part-of the microcredit system and separate from it-has significant potential to improve the health status of the poor.

Micro-insurance for health in India: Yeshasvini Cooperative Farmers Health Scheme

The Yeshasvini Cooperative Farmers Health Scheme-started in 2003 in Karnataka-covers 1.45 million members (at its zenith there were 2.2 million members which fell after premiums were doubled). The insurance is offered in partnership with cooperatives which has been an effective distribution channel but outreach to women is limited as cooperative members are primarily men. Yeshavini was designed to be self-financed but the Indian Government insisted on subsidizing the premium (13).

In contrast to micro-insurance for health in Bangladesh, the benefit package focuses on high-cost/lowfrequency events. Over 1,600 different surgeries are covered at the network hospitals where there are fixed prices for each surgery, including connected costs, e.g. follow-up consultations. Network hospitals are mainly private hospitals. The prices fixed by Yeshavini with participating hospitals are about $30 \%$ below the average price charged (13).

The maximum benefit per person per year is Rs 200,000 (US\$ 4,550) for an annual premium of Rs 120. Benefits also include free outpatient treatment. The insurer pays the healthcare provider for preapproved surgeries and outpatient treatment; so, the service is cashless to the policy-holder (13).

Risk-management through integrated insurance: VimoSEWA in India

VimoSEWA, started offering an integrated insurance product in 1992 and is a trust operated by the
SEWA Union which also includes rural cooperatives, microcredit, trade facilitation centres, health services, SEWA bank, a housing trust, and daycare services. VimoSEWA has strong links with other parts of the SEWA Union, particularly in distribution and marketing of insurance products. Over time, VimoSEWA has experimented with different business models, providing insurance directly and with private-sector partners. The liberalization of the insurance market and the requirement for private-sector insurers to serve the low-income market has boosted the ability of VimoSEWA to negotiate a package of services that meets the needs of the poor. Currently, VimoSEWA uses a partner-agent model where the insurer is a private company, and VimoSEWA is the distributor and provider of the insurance services. Therefore, VimoSEWA carries very little insurance risk. This risk-management and service model was established after trying different structures and after the experience of severe financial liabilities due to a natural disaster.

In 2001, VimoSEWA developed a business plan with the goal of achieving financial sustainability. The business plan assumed that the scheme could be scaled up to reach 300,000 members and viability within seven years. However, membership remains below the targets, and it is estimated that financial viability will not be reached before 2012 . Low renewal rates have been the primary limiting factor in reaching financial viability. Nonetheless, the business plan has helped VimoSEWA progress towards a more professional approach to the scheme. They have improved management skills and knowledge, management information system, risk management, and setting of objectives.

VimoSEWA offers an integrated insurance product, including life, widow insurance in the event of death of spouse, health, and asset insurance. Only women can take out a policy but they can cover themselves and their spouse, or the entire family. The integrated insurance product imposes risk-pooling on members and reduces adverse selection for specific types of insurance. In fact, the insurance is marketed as a community risk-management tool, not a benefit scheme. Health insurance is the most-used benefit. The average submitted claim is Rs 2,670 (US\$ 61), and 51\% of claims reach the maximum benefit.

One important lesson that micro-insurance can learn from VimoSEWA is the need for re-insurance to manage risk. In 2001, VimoSEWA was self-insuring, i.e. providing insurance directly without the 
backing of a private-sector insurer. In January of that year, the earthquake devastated the Gujarat state. Claims under the asset and loss component of their insurance were over US\$ 75,000 , which put VimoSEWA under severe financial strain. Prior to the Gujarat earthquake, annual pay-outs for asset protection were less than US\$ 662. Re-insurance would have covered this type of covariate risk; it is commonly used by insurance companies to cover the major catastrophic events when claims far exceed those in an average year. This example illustrates that, to provide support properly when the poor need it most, micro-insurers must follow the professional norms of standard insurance companies, particularly when it comes to management of risk (14).

\section{IMPACT ON EXCLUSION FROM HEALTH SERVICES}

The examples shown demonstrate that microinsurance for health can reduce exclusion from basic health services. While in Bangladesh, focus of micro-insurance for health on primary health service does not fully address economic exclusion from essential, high-cost healthcare, the microinsurance schemes for health in Bangladesh have increased access to basic health services for the poor, particularly the female participants. Having the micro-insurance-affiliated medical facilities encourages participants to seek medical advice from formally-trained care providers in the early stage of an illness. Previously, initial medical advice would be taken from traditional practitioners or be selftreated. Only once an illness became serious, would formal medical advice be sought (10).

The micro-insurance schemes for health in Bangladesh have been structured to enhance capabilities, resources, and skills of women. As such, they can reduce the exclusion of women from basic resources of the society. However, the strength of the relationship between micro-insurance for health and reduced social exclusion of women in Bangladesh has yet to be quantified.

Women are the primary and target market for micro-insurance for health. In most cases in Bangladesh, household medical services covered by insurance are accessed through female card-holders. In the case of facilities established by the micro-insurance schemes for health, clinics are largely run by women, and women are trained as professional health workers to service the majority of female clientele (11). Through micro-insurance facilities for health and low or no-cost services, women are able to independently access health services without assistance from male family members either for funding or transportation. Women can go to a local clinic and use an insurance card to receive health services. Some micro-insurance schemes for health target specific socially-excluded populations. For example, the Society for Social Services has programmes for ethnic minorities, sex workers, and working children (10).

With regard to economic exclusion and healthcare, the impact of micro-insurance for health appears to be mixed. Micro-insurance may increase access to primary healthcare by decreasing the cost of basic healthcare, but at least as benefits are designed in Bangladesh, micro-insurance for health does not reduce the likelihood that health-related costs will be a catastrophic expense for a household.

Primary healthcare is extremely important to improve health at the population level in Bangladesh, and the micro-insurance schemes for health are focused on that segment of healthcare. However, there are unmet health needs for surgeries and more expensive medical procedures among the poor, which remain unaddressed by basic microinsurance for health. For instance, results of research in Bangladesh showed significant inequalities in access to caesarean birth services (Anwar I, Collins S, Ronsmans C. A decade of inequality in maternity care: trends in professional attendance and caesarean section in Bangladesh, 1991-2004. Dhaka: International Centre for Diarrhoeal Disease Research, Bangladesh, 2006 [Unpublished]). Among the general population, approximately 10$15 \%$ of deliveries are generally expected to require caesarean-section surgery. In Bangladesh, caesarean-section births among the poor are less than $1 \%$ (Fig.) (ibid). Public-sector services are not meeting needs, particularly of the poor and the poorest. As currently designed and offered in Bangladesh, the micro-insurance schemes for health cannot help address this unmet need. As a further example of the inability of micro-insurance for health in Bangladesh to address unmet medical needs, the average claim from VimoSEWA clients is greater than Rs 2,500 (US\$ 57), which is above the maximum benefit for most micro-insurance schemes for health in Bangladesh (14).

In addition, basic health insurance does not address catastrophic health expenses, and health costs are the most likely cause of a household crisis. The study on rickshaw-pullers in Dhaka found that half of crisis-related expenses among respondents were due 


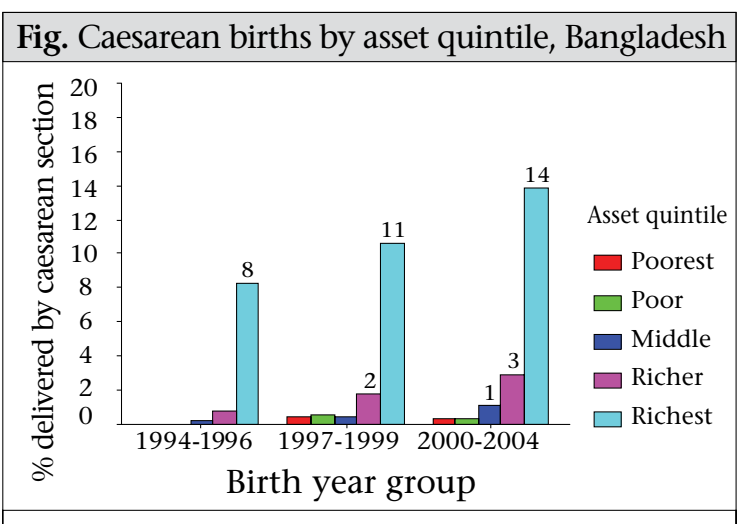

Source: Anwar I, Collins S, Ronsmans C. A decade of inequality in maternity care: trends in professional attendance and caesarean section in Bangladesh 1991-2004. Dhaka: International Centre for Diarrhoeal Disease Research, Bangladesh, 2006 (Unpublished)

to health (12). Costs of a health crisis averaged Tk 6,000 (US\$ 87) among a population in which half cannot generate any surplus from income and onefifth cannot afford three meals a day. The full economic burden of health costs can be catastrophic. On top of the direct cost, productivity and, therefore, income are likely to be reduced after ill-health, which can put a household into a downward spiral. Ill-health, crisis expenditure, and lower productivity lead to falling incomes, which, in turn, negatively affect the health and education status of children, leading to lower human capital investment and an intergenerational cycle of chronic poverty (12).

Measures of the poverty impact of healthcare payments highlight the importance of out-of-pocket payments in pushing people into poverty and keeping them in poverty. Households are defined as being below the poverty-line based on their household expenditure. Therefore, high out-ofpocket health expenditure may actually raise spending above this measure of the poverty-line, even if health expenditure has been made by reducing food, clothing and shelter expenses to a below poverty-line level. To measure the poverty impact of health expenditure, out-of-pocket health payments are subtracted from overall household resources to calculate a post-health payment poverty head-count. Excluding payments for healthcare from household resources in the 1999-2000 Household Income Expenditure Survey in Bangladesh increases the number of people living below US\$ 1 per day by $3.8 \%$, or 4.9 million individuals. The same calculation with a US\$ 2 per day poverty-line increases the poverty head-count by an additional $3.6 \%$. The same study found that payments for healthcare also increase the poverty gap, i.e. the amount by which households are below the poverty-line as illustrated in Table 3 (15).

The high rates of out-of-pocket and catastrophic health payments exacerbate the prevalence and depth of poverty in Bangladesh. Micro-insurance for health in Bangladesh does not address this point and, hence, is not preventing health expenditure from pushing households into poverty and keeping them in poverty.

There is a trade-off among micro-insurance system costs, financial viability, and risk protection. Insurance coverage that is affordable and financially viable (covering more limited services) is likely to be less successful in avoiding catastrophic health costs (16). Therefore, based on this limited analysis, the preliminary answers to the questions posed at the beginning of the case study are that micro-insurance for health increases access to, and use of, basic formal-sector health services among excluded populations but does not reduce the likelihood that health-related costs incurred would be a catastrophic expense for a marginalized household, pulling the household deeper into poverty.

Table 3. Poverty impact (\%) of out-of-pocket health expenditure for Bangladesh (15)

\begin{tabular}{|lcc|}
\hline \multirow{2}{*}{ Poverty impact } & \multicolumn{2}{c|}{ Poverty-line } \\
\cline { 2 - 3 } & US\$ 1 per day & US\$ 2 per day \\
\hline Pre-health payment poverty headcount & 22.5 & 73.0 \\
Post-health payment poverty headcount & 26.3 & 76.5 \\
Percentage point increase in poverty & & \\
incidence due to OOP health payments & 3.8 & 3.6 \\
Pre-health payment poverty gap & 4.5 & 27.8 \\
Post-health payment poverty gap & 5.3 & 30.5 \\
Percentage point increase in poverty gap & & 2.6 \\
due to OOP health Payments & 0.9 & \\
\hline $\begin{array}{l}\text { Poverty gap is the average amount by which resources fall short of the poverty-line as a percent- } \\
\text { age of that line; OOP=Out-of-pocket }\end{array}$ & \\
\hline
\end{tabular}




\section{CURRENT POLICY ACTIONS}

In Bangladesh, the insurance industry denationalized in the mid-1980s is regulated by the Chief Controller of Insurance. The Bangladesh Insurance (Nationalisation) Order of 1972 and the Insurance Act (1938, revised 2001) provide the legislative and basis for regulation. Although no direct regulations aimed at micro-insurance, a number of provisions can potentially impact micro-insurance (17).

- Insurers cannot transact both life and health insurance. Therefore, an integrated insurance product like that offered by VimoSEWA is probably not possible in Bangladesh in the current regulatory environment.

- To protect policy-holders, regulation limits insurance management expenses to $38 \%$ of premiums. Given that micro-insurance typically has higher overhead costs (i.e. management expenses are a higher percentage of premiums), this maximum may limit micro-insurance products and companies, especially at the initial stages of introduction.

- Qualification requirements for insurance agents may limit the use of microfinance staff for micro-insurance sales.

- Various institutional options are available for funding insurance, e.g. mutual insurance and provident funds. These options may be appropriate for micro-insurance.

- Funding of the Insurance Directorate through insurance premiums. The Insurance Directorate is funded through a $0.15 \%$ (scheduled to increase to $0.35 \%$ ) fee on insurance premiums. This increase in the fee (to $0.35 \%$ ) may negatively impact provision of insurance to the low-income market that cannot pay higher premiums (17).

The India examples provide illuminating contrasts to the micro-insurance schemes for health in Bangladesh. India liberalized its insurance market in 1999 when the insurance market was opened to private insurers and limited foreign ownership was permitted. The Insurance Regulatory and Development Authority (IRDA) in India has taken an interest in micro-insurance in a number of ways. First, all insurance companies are required to serve rural areas and persons below the poverty-line. Each private company must insure at least 25,000 lowincome lives by the end of five years of operations. Public insurers must increase the number of lowincome policy-holders each year. For the most part, private insurers view this requirement as a cost of doing business and have not pursued the lowincome segment as a viable market. Second, the IRDA has proposed specific micro-insurance regulations. NGOs can only offer micro-insurance in collaboration with a regulated insurance company and can receive commission from the insurer for services provided. The capital requirements are high for micro-insurers who want to establish a regulated entity but can provide insurance through a trust (14).

The insurance and micro-insurance regulatory environment in India may provide important lessons for regulators in other countries. The liberalization of the insurance market, combined with the requirement for private-sector insurers to serve the low-income population, has led to a competitive and high-quality micro-insurance market in India.

\section{DISCUSSION}

Different micro-insurance schemes for health are designed to solve specific problems. Microinsurance for health in Bangladesh appears to be designed to increase access to, and use of, basic healthcare. The Indian schemes, on the other hand, are aimed at improving quality and reducing the income impact of secondary and tertiary healthcare. Based on this analysis, to increase the impact by better addressing the health needs of the poor and the otherwise excluded, micro-insurance for health should: (a) cover high cost but necessary procedures and (b) expand membership to a wide range of low- and middle-income groups to increase cross-subsidization and improve financial viability. However, further research should establish whether micro-insurance for health is suited to addressing the basic and catastrophic health expenses. Competition and experimentation can help answer this question, when combined with knowledge-sharing and critical analysis.

There is a significant scope and need for donor assistance to micro-insurance in general and micro-insurance schemes for health in particular. Technical assistance can help the micro-insurance schemes for health improve the management capacity and systems, including risk-management through re-insurance. Technical assistance can also focus on connecting micro-insurance to overall development of the financial sector. Micro-insurance programmes must invest their portfolio of funds in a manner that is appropriate to their fiduciary risks and that benefits the growth of the community. The example of VimoSEWA's difficulties after earthquake in Gujarat demonstrate the need for micro- 
insurance programmes to use re-insurance; this requires an understanding (through actuary analysis) of the risks that a micro-insurance programme is taking and a risk-management strategy. In many developing countries, the insurance sector remains under-developed. If the design and growth of the micro-insurance sector can incorporate modern concepts of actuary analysis, management information systems, portfolio management, and riskmanagement, it will assist the overall development of the insurance sector and mobilization of domestic investment capital.

For donors, the guiding principle for identifying successful micro-insurance programmes for health should be based on both health impact and financial viability. Micro-insurance managers and donors should use financial sustainability as an indicator of demand and management skill. The CGAP donor guidelines (http://www.cgap.org/p/site/c/donors) can provide details of indicators to guide evaluation and monitoring. To assist micro-insurers to achieve financial viability, donors should have a long-term time horizon, provide endowment funding rather than subsidizing operational shortfalls, and should coordinate their assistance and monitoring requirements.

To design appropriate micro-insurance and microinsurance programmes for health, research should be carried out to quantify the impact of specific types of micro-insurance for health on out-of-pocket health expenses; incidence of poverty and poverty gap; inter-generational transfer of poverty; use of health services; and household health status.

Finally, micro-insurance for health and/or its tools and methods can be an important part of a country's public-health strategy. High levels of catastrophic and out-of-pocket payments among the poor and ultra-poor could be addressed through a micro-insurance system for health that allows services to be accessed from public, private, or NGO medical facilities. Bangladesh could examine effective health-card schemes, such as those in place in Thailand and Indonesia, to develop public-health and micro-insurance schemes that meet the needs of the poor and ultra-poor.

This analysis has limitations. It is based on existing data; no original data have been presented. Clearly, there is a need for dedicated independent research, comparing the impact of micro-insurance for health and public-sector programmes on reducing exclusion among target populations. Additionally, there is a need to develop, test, and imple- ment quantitative indicators that can be used for measuring the impact of different interventions on changing degrees of spatial and economic exclusion. Such indicators should be used as part of the monitoring of the impact of the micro-insurance programme for health.

\section{CONCLUSION}

This analysis of micro-insurance schemes in Bangladesh with contrasting examples from India demonstrates the potential that these programmes have to reduce poverty and otherwise improve the health status of the poor. Micro-insurance programmes for health have reduced barriers to health services for the poor and encouraged them to avail of clinics and trained medical care providers for basic and preventative healthcare. The rural and urban poor have traditionally turned to self-treatment (minimally-trained village pharmacist) or traditional healers. Micro-insurance facilitates access to professional healthcare at early stages and offers opportunities to provide accurate health information and primary healthcare interventions. In this way, the micro-insurance schemes for health in Bangladeshi have increased access to basic healthcare.

However, there is both demand and necessity for surgeries and more expensive medical procedures among the poor that remains unaddressed by basic micro-insurance for health. Bangladesh has some of the highest rates of out-of-pocket and catastrophic health-related payments, which have a significant impact on poverty. High-cost healthcare, not covered by basic micro-insurance for health, is still a significant impoverishing expense for the poor. As micro-insurance schemes for health expand, strong efforts will be needed to design a financiallyviable insurance product that covers surgeries and high-cost medical services to meet the needs of the poor.

Micro-insurance can serve the interests of poor populations with risk-pooling to manage unpredictable employment, flows of income, and catastrophic events. To ensure that micro-insurance safeguards the assets and interests of the poor, micro-insurance initiatives must exercise professional management, product development, management information systems, and re-insurance.

\section{ACKNOWLEDGEMENTS}

This work was made possible through funding provided by the World Health Organization (WHO) to ICDDR,B and was undertaken as work for the Social Exclusion Knowledge Network established as 
part of the WHO Commission on the Social Determinants of Health. The views presented in this paper are those of the author and do not necessarily represent the decisions, policy, or views of WHO or Commissioners.

\section{REFERENCES}

1. Carr D. Improving the health of the world's poorest people. Health Bull 2004;(1):1-34.

2. Roth J, McCord M, Liber D. The landscape of microinsurance in the world's 100 poorest countries. Appleton, WI: MicroInsurance Centre, Limited Liability Company, 2007. 107 p.

3. World Health Organization. Core health indicators database: 2004 data. (http://www.who.int, accessed on 2 June 2007).

4. International Labour Organization. Micro health insurance: profile of community based schemes in Bangladesh. Dhaka: Women's Empowerment through Employment and Health, International Labour Organization Bangladesh, 2003:3-43.

5. Van Doorslaer E, O'Donnell O, Rannan-Eliya RP, Somanathan A, Adhikari SR, Garg CC et al. Catastrophic payments for health care in Asia. Health Econ 2007;16:1159-84.

6. Xu K, Evans DB, Kawabata K, Zeramdini R, Klavus J, Murray CJ. Household catastrophic health expenditure: a multicountry analysis. Lancet 2003;362:111-7.

7. O'Donnell, Owen, van Doorslaer E, Rannan-Eliya RP, Somanathan A, Adhikari SR et al. The incidence of public spending on healthcare: comparative evidence from Asia. World Bank Econ Rev 2003;21:93-123.

8. Frenk J, Poverty, health and social protection. In: Proceedings of International Conference on Social Health Insurance in Developing Countries. Eschborn: Deutsche Gesellschaft fur Technische, 2005:1. (www.shi-conference.de/berlin_2005_1.php, accessed on 31 May 2007).

9. International Labour Organization. Micro insurers: inventory of micro insurance schemes in Bangladesh. Dhaka: Women's Empowerment through Employment and Health Project, International Labour
Organization Bangladesh, 2003. 57 p.

10. Ahmed M, Islam SK, Quashem M, Ahmed N. Health microinsurance: a comparative study of three examples in Bangladesh. Washington, DC: CGAP Working Group on Microinsurance, World Bank, 2005:1-61. (Good and bad practices case study no. 13).

11. International Labour Organization. Grameen Kalyan and BRAC: assessment of micro health insurance schemes. Dhaka: Women's Empowerment through Employment and Health Project, International Labour Organization Bangladesh, 2004. 42 p.

12. Begum S, Sen B. Unsustainable livelihoods, health shocks and urban chronic poverty: rickshaw pullers as a case study. Manchester: Chronic Poverty Research Centre, 2004. 26 p. (Chronic Poverty Research Centre working paper no. 46).

13. Radermacher R, Wig N, van Putten-Rademaker O, Müller V, Dror D. Yeshasvini Trust. Washington, DC: CGAP Working Group on Microinsurance, World Bank, 2005:45. (Good and bad practices case study no. 20).

14. Garand D. VimoSEWA: India. Washington, DC: CGAP Working Group on Microinsurance, World Bank, 2005:49. (Good and bad practices case study no. 16).

15. van Doorslaer E, O'Donnell O, Rannan-Eliya RP, Somanathan A, Adhikari SR, Garg CC. Effect of payments for healthcare on poverty estimates in 11 countries in Asia: an analysis of household survey data. Lancet 2006;368:1357-64.

16. Xu K, Evans DB, Carrin G, Aguilar-Rivera AM. Designing health financing systems to reduce catas-trophic health expenditure. Geneva: World Health Organization, 2005. 8 p. (Technical briefs for policy-makers no. 2).

17. McCord MJ, Churchill C. Delta Life, Bangladesh. Washington, DC: Consultative Group to Assist the Poor Working Group on Microinsurance, World Bank, 2005:1-65. (Good and bad practices case study no. 7). (http://www.microfinancegateway. org/p/site/m// template.rc/1.9.26113, accessed on 2 June 2009). 


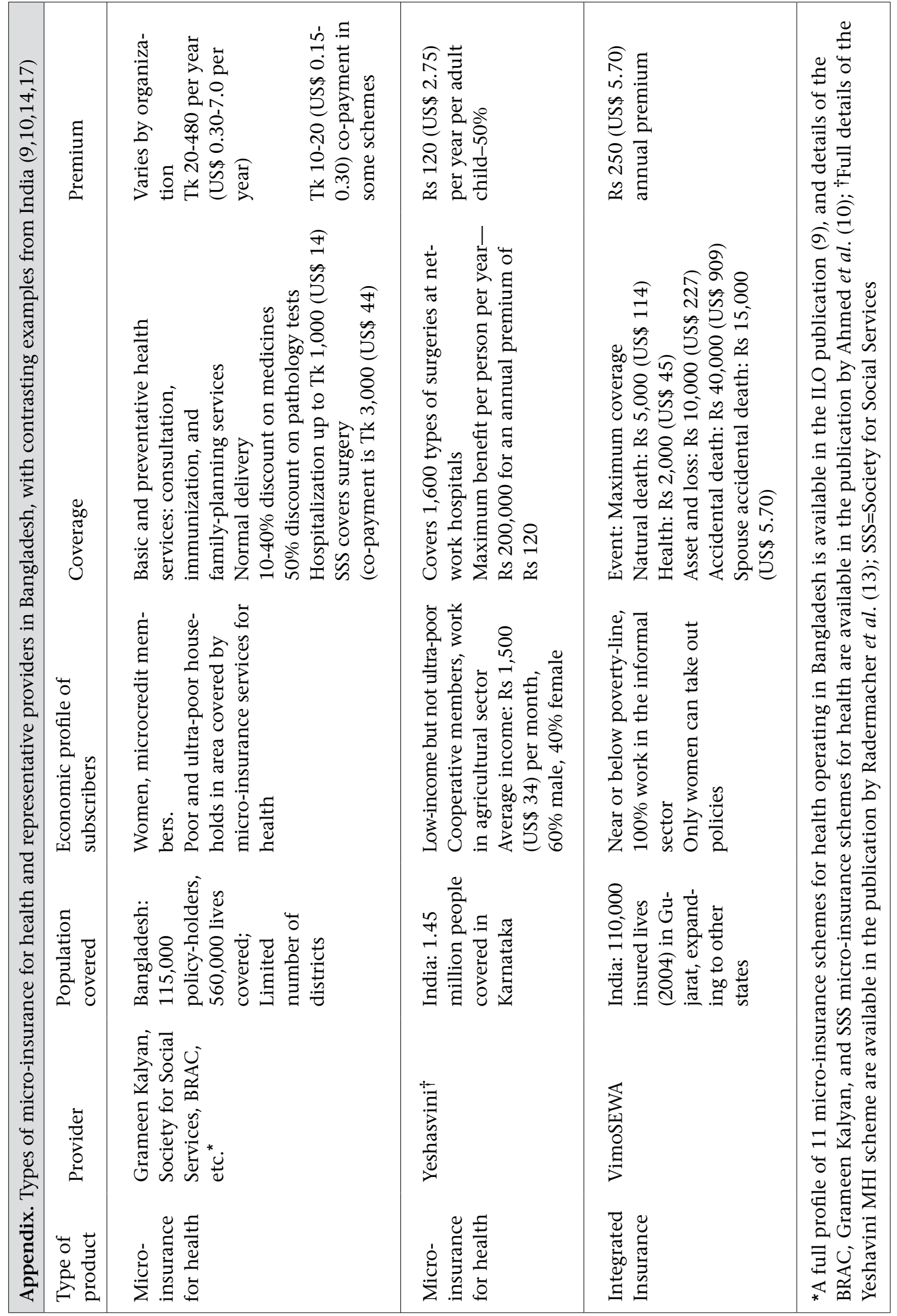

